\title{
ANALISIS KINERJA UNIT RAWAT INAP RUMAH SAKIT X BERDASARKAN KRITERIA MALCOLM BALDRIGE
}

\author{
Setya Haksama ${ }^{1)}$, M. Farid Dimyati Lusno( ${ }^{1)}$, Diansanto Prayoga ${ }^{1}$, M. Rifqo Hafidzudin \\ Farid $^{2)}$,Syadza Syahrah Shedyta ${ }^{2)}$, Syahrania Naura Shedysni' ${ }^{3)}$, Sri Wiwoho Mudjanarko' ${ }^{4)}$ \\ ${ }^{1}$ Faculty of Public Health, Universitas Airlangga \\ ${ }^{2}$ Ngimbang Hospital, District of Lamongan \\ ${ }^{3}$ Faculty of Medicine, Universitas Airlangga \\ ${ }^{4}$ Narotama University \\ Email : setyahaksama@ fkm.unair.ac.id
}

\begin{abstract}
Pengukuran kinerja di rumah sakit saat ini merupakan hal yang sangat penting dan perlu dilakukan terutama dalam kondisi persaingan pelayanan kesehatan di rumah sakit sangat ketat terutama terkait dengan kinerja pelayanan, sehingga tujuan penelitian ini adalah mengukur kinerja pelayanannya dengan baik dan seksama. Salah satu metode yang digunakan adalah pengukuran intsrumen kinerja berdasarkan MalcolmBaldrige Performance Criteria. Penelitian ini merupakan observasional analitik dengan disaincrosssectional yang bertujuan untuk melihat hubungan antar variabel. Jumlah responden 50 orang pegawai terdiri dari perawat, bidan, asisten perawat, dan asisten bidan di unit rawat inap Rumah Sakit $X$. Analisis data dari variabel penelitian dilakukan dengan penghitungan nilai dari kriteria kinerja Malcolm Baldrige. Hasil penelitian ini menunjukkan bahwa kinerja Rumah Sakit X berdasarkan profil organisasi memiliki skor 74,50; kepemimpinan 86,75 (72,29\%); perencanaan strategis 66,50 (78,24\%), fokus pelanggan $63,45(74,62 \%)$; pengukuran, analisis, dan manajemen pengetahuan $66,83(74,25 \%)$, fokus operasi 64,28 (75,62\%), dan skor hasil 348,65 dari 5 hasil yang memiliki 77,48\%, dan kriteria sangat baik. Kinerja Rumah Sakit X termasuk dalam kategori sangat baik pada kriteria perencanan strategis, focus sumber daya manusia, focus operasional, dan kriteria hasil; dan pada kriteria kepemimpinan, focus pelanggan, dan pengukuran analisis dan manajemen pengetahuan berada pada kategori baik dengan nilai keseluruhan adalah 762.35 yang berada pada kategori sangat baik. Rekomendasinya adalah Rumah Sakit X tetap perlu fokus meningkatkan dan mempertahankan kinerjanya dengan senantiasa melakukan monitoring dan pengawasan pada kriteria dengan nilai sangat baik, dan perlu diukur secara terus menerus untuk melihat trend pelayanannya.
\end{abstract}

Keywords: Malcolm Baldrige Performance Criteria, Performance Measurement, hospital performance)

\section{PENDAHULUAN}

Pengukuran kinerja di rumah sakit saat ini merupakan hal yang sangat penting dan perlu dilakukan dalam rangka peningkatan kualitas pelayanan kepada masyarakat. Persaingan pelayanan kesehatan di rumah sakit sangat ketat terutama terkait dengan kinerja pelayanan, sehingga setiap rumah sakit perlu senantiasa mengukur kinerja pelayanannya dengan baik dan seksama (Haksama, 2016). Pada era saat ini peran kinerja menjadi sangat penting karena terkait dengan pelayanan yang diberikan oleh rumah sakit, selain itu kinerja yang baik dapat meningkatkan mutu pelayanan yang diberikan. Salah satu kinerja utama RS adalah efisiensi penggunaan tempat tidur, sumberdaya manusianya, dan penggunaan 
fasilitasnya. Salah satu intsrumen untuk mengukur kinerja adalah Malcolm Baldrige Performance Criteria sebagai metoda menganalisis kinerja (Abqari dan Haksama, 2013).

Saat ini banyak rumah sakit yang tingkat huniannya relatif rendah yang diukur dengan Bed Occupancy Rate (BOR), Asmaliza, Fuad, dan Utarini (2007) menyatakan bahwa BOR yang rendah terkait dengan manajemen dan kinerja rumah sakit yang rendah. Menurut Nurhapna dan Haksama (2014) menyatakan bahwa butuh startegi yang baik untuk meningkatkan pelayanan di rumah sakit agar penggunaan tempat tidur dapat ideal sesuai dengan standar yang ditetapkan.

\section{TINJAUAN PUSTAKA}

\section{Berisi Rumah Sakit}

Berdasarkan Undang-undang Nomor 44 tahun 2009 tentang Rumah Sakit, menyebutkan bahwa rumah sakit adalah sarana pelayanan kesehatan yang menyelenggarakan pelayanan kesehatan perorangan meliputi pelayanan promotif, preventif, kuratif, dan rehabilitatif yang menyediakan pelayanan rawat inap, rawat jalan, dan gawat darurat.

Rumah sakit mempunyai tujuan utama dalam memebrikan pelayanan yang sesuai dengan kebutuhan pasien yang dapat memberikan pelayanan prima dan bermutu (Haksama, 2016).

\section{Pengukuran Kinerja Rumah Sakit}

Indikator pengukuran kinerja rumah sakit untuk menggambarkan kinerja suatu rumah sakit yang terkait dengan mutu, efisiensi, pemanfataan, dan pelayanan terdiri dari 4 (empat) hal, yakni 1). Bed Occupancy Rate (BOR), merupakan rasio hunian tempat tidur rawat inap rata-rata dalam periode tertentu. Nilai ideal BOR adalah berkisar 75\%-85\%; 2). Bed Turn Over (BTO), merupakan angka yang menunjukkan frekuensi pemakaian tempat tidur dalam satu satuan waktu tertentu, yang menunjukkan berapa kali dalam satu tahun rata-
Masalah yang diangkat dalam penelitian ini adalah kinerja unit rawat inap RS X belum optimal dimana tingkat efektivitas dan efisiensi masih rendah, dimana BOR tahun 2016 65,49\% dan di tahun 2017 menjadi 56,31\%.Hal in menunjukkan bahwa BOR selain belum optimal sesuai dengan standar kemenkes yang tercantum pada Kepmenkes Nomor 129 tahun 2008 tentang Standar Pelayanan Minimal Rumah Sakit, namun juga cenderung menurun jumlah kunjungannya. Penelitian ini menganalisis kinerja unit rawat inap Rumah Sakit X berdasarkan kriteria kinerja Malcolm Baldrige.

rata semua tempat tidur rumah sakit digunakan. Nilai ideal dalam satu tahun rata-rata semua tempat tidur terpakai lebih 30 kali;3). Turn Over Interval (TOI), merupakan interval rata-rata hari tempat tidur kosong, yakni menunjukkan rata-rata hari tempat tidur tidak ditempati hingga digunakan oleh pasien berikutnya dengan nilai ideal adalah 1-3 hari; dan 4). Average Length of Stay (ALOS), merupakan rata-rata lama hari perawatan seorang pasien di rumah sakit yang menggambarkan efektivitas dan efisiensi rawat inap yang baik, idealnya adalah3 sampai 12 hari.

\section{Kriteria Kinerja Malcolm Baldrige}

Kriteria kinerja Malcolm Baldrigepada dasarnya merupakan kriteria inti dari Malcolm Baldrige Performance Criteria yang diciptakan pertama kali oleh US Congress dan berada di bawah tanggung jawab the National Institute of Standards and Technology (NIST) yakni lembaga penelitian di bawah Departemen Perdagangan Amerika Serikat terkait dengan pelaksanaan bisnis manufaktur, jasa, dan bisnis kecil.

Kriteria kinerja Malcolm Baldrige terdiri dari profil organisasi dan mempunyai tujuh kriteria inti yakni: kepemimpinan, perencanaan 
strategik, fokus pelanggan, pengukuran, analisis, dan manajemen pengetahuan, fokus sumberdaya manusia, fokus kegiatan operasional, kriteria hasil (Gaspersz, 2011).

Menurut National Institute of Standards and Technology (2011) tujuan dari kriteria Malcolm Baldrige adalah: 1). Membantu meningkatkan praktek kinerja organisasi, kemampuan, dan hasil; 2). Memudahkan komunikasi dan sharing informasi tentang praktek terbaik antar organisasi; dan 3). Berfungsi sebagai alat manajemen untuk memahami dan mengelola kinerja serta untuk pedoman perencanaan dan kesempatan untuk pembelajaran.

\section{Profil Organisasi}

Merupakan gambaran kondisi karakteristik organisasi yang hendak diukur kinerja manajemennya dengan melakukan pengukuran awal dan mengidentifikasi gap antara standar kinerja dengan hasil yang dicapai, dan tantangan ke depan yang dihadapi organisasi (Brown, 2008).

\section{Kriteria Kepemimpinan}

Kepemimpinan merupakan aspek sangat penting berupa kemampuan pemimpin dalam memandu dan mengelola organisasi, kemampuan pemimpin dalam berkomunikasi, kepatuhan terhadap hukum dan etika, dan bagaimana kepemimpinan organisasi memperkuat dan memberdayakan komunitas sebagai bentuk social responsibility(Sholihah dan Haksama, 2014).

\section{Kriteria Perencanaan Strategik}

Merupakan kriteria untuk menyusun rencana strategik dan rencana tindakan organisasi dengan melibatkan berbagai sumberdaya berdasarkan pihak yang dilibatkan, aspek kekuatan, kelemahan, peluang, dan ancaman organisasiyang dapat dilakukan untuk pelaksanaan strategi di seluruh lingkungan organisasi (Brown, 2008).

\section{Kriteria Fokus Pelanggan}

Kriteria fokus pelanggan mengidentifikasi potensi pelanggan dan segmen pasar, menghimpun umpan balik dari elanggan segmen pasar, dan bagaimana organisasi memanfaatkan umpan balik yang ada untuk mengidentifikasi peluang baru (Abqari dan Haksama, 2013).

Kriteria Pengukuran, Analisis, dan

\section{Manajemen Pengetahuan}

Kriteria pengukuran, analisis, dan manajemen pengetahuan merupakan pengukuran kinerja untuk jangka pendek dan jangka panjang melalui pengumpulan data dan informasi untuk dukungan pelaksanaan operasional, pengambilan keputusan strategik, dan inovasi baru. Manajemen pengetahuan merupakan pengelolaan dan penataan pengetahuan, dimana hal ini dibutuhkan untuk bagaimana pengetahuan dapat disimpan, didelivery-kan kepada para pelanggan, pemasok, dan mitra usaha untuk dipakai dalam perencanaan strategik. Hasil kriteria ini merupakan dokumen yang dapat digunakan sebagai bentuk dukungan dalam pengambilan keputusan dan disebarkan ke organisasi (Haksama, 2016).

\section{Kriteria Fokus Sumber Daya Manusia}

Kriteria fokus SDM terdiri dari sistem rekrutmen, seleksi, mempertahankan dan melibatkan SDM yang ada, kepuasan SDM, mewujudkan budaya organisasi untuk mencapai kinerja tinggi, pemberian kompensasi, penghargaan, pengakuan, dan insentif SDM (Brown, 20018). Sedangkan peran SDM juga diarahkan untuk memperkuat fokus pelanggan dan pencapaian rencana kerja.

\section{Kriteria Fokus Operasional}

Kriteria fokus operasional merupakan substansi dari kompetensi inti seperti misi, lingkungan kompetitif, dan rencana kerja yang terkait dengan efisiensi, efektivitas, dan sistem di organisasi. Proses kerja diutamakan untuk meminimalkan kesalahan dan kerugian yang 
terjadi sehingga dapat meningkatkan inovasi dan kinerja organisasi.

\section{Kriteria Hasil}

Terdapat 5 (lima) kriteria Malcolm Baldrige untuk indikator kriteria hasil meliputi: 1). Hasil produk pelayanan dan efektivitas proses operasionalterdiri dari kinerja pelanggan dan perbandingannya dengan pesaing, tingkat dan tren kinerja operasional dari sistem dan proses kerja, dan peningkatan proses terus menerus; 2). Hasil fokus pelanggan terdiri dari

\section{METODOLOGI}

Penelitian ini adalah observasional analitik dengan disain cross sectional yang bertujuan untuk melihat hubungan antar variabel. Jumlah responden dalam penelitian ini diambil secara acak sebesar 50 orang yang merupakan pegawai yang menduduki jabatan struktural dan fungsional yang berprofesi sebagai perawat, bidan, asisten perawat, dan asisten bidan di unit rawat inap ruang dewasa, ruang anak, ruang bersalin, dan ruang neonatus Rumah Sakit X. sedangkan waktu penelitian dilaksanakan selama bulan Oktober tahun 2016.

Analisis data dari variabel penelitian dilakukan secara deskriptif menggunakan

\section{HASIL DAN PEMBAHASAN}

\section{Gambaran Umum Rumah Sakit X}

Rumah Sakit X merupakan Rumah Sakit Umum Daerah (RSUD) di salah satu kota di wilayah Provinsi Jawa Timur yang berdiri pada awal tahun 1917 yang dibangun secara gotong royong. Pada beberapa tahun yang lalu rumah sakit selesai dibangun dengan memiliki 100 TT (tempat tidur) dan menjadi rumah sakit tipe C.Rumah sakit ini berada dijalan raya tingkat kepuasan, persepsi dan penilaian, dan loyalitas pelanggan berdasarkan tren kinerja saat ini dibandingkan dengan tingkat kepuasan pesaing; 3). Hasil pasar dan finansial terdiri dari peningkatan penjualan, pangsa pasar, keuntungan, dan Return on Investment (ROI); 4). Hasil SDM terdiri dari kompetensi dan pembelajaran, kepuasan SDM, dan tingkat keterlibatan SDM; dan 5).Hasil kepemimpinan terdiri dari pencapaian strategi dan rencana kerja, kepatuhan terhadap hukum dan peraturan, dan bentuk tanggung jawab sosial.

distribusi frekuensi, penghitungan bobot, dan penghitungan nilai berdasarkan pada nilai kriteria kinerja Malcolm Baldrige. Hasil penghitungan tersebut selanjutnya dikalikan dengan nilai maksimal Malcolm Baldrige.

Penilaian yang digunakan adalah $0.00 \%$ hingga $25.00 \%$ sangat kurang; $>25.00 \%$ hingga $50.00 \%$ kurang; $>50.00 \%$ hingga $75.00 \%$ baik; dan di atas $75.00 \%$ sangat baik. Sedangkan untuk nilai keseluruhan dijelaskan sebagai berikut: 0-250 sangat kurang; >250-500 kurang; $>500-750$ baik; dan >750 sangat baik.

utama Daendels yang menghubungkan ibu kota provinsi dengan ujung timur wilayahnya. Pengukuran Kinerja Organisasi Berdasarkan Kriteria Kinerja Malcolm Baldrige

Hasil dari pengukuran kinerja organisasi berdasarkan pada kriteria kinerja Malcolm Baldrige terdapat pada table di bawah ini sebagai berikut. 
JurnalSainHealth Vol. 2 No.2 Edisi September 2018

(c) Fakultas Ilmu Kesehatan Universitas Maarif Hasyim Latif Sidoarjo

p-ISSN : 2548-8333

e-ISSN : 2549-2586

Tabel. 1 Hasil Pengukuran Kinerja Organisasi

\begin{tabular}{|c|c|c|c|c|c|}
\hline Categories & $\begin{array}{c}\text { Standar } \\
\text { Point }\end{array}$ & $\begin{array}{l}\text { Item } \\
\text { Point }\end{array}$ & $\begin{array}{l}\text { Total } \\
\text { Point }\end{array}$ & $\%$ & Criteria \\
\hline Organizational Profiles & & 74.50 & & & \\
\hline 1. Leadership & 120 & & & & \\
\hline a. Senior Leadership & 70 & 50.75 & & & \\
\hline b. Governance and Societal Responsibilities & 50 & 36.00 & 86.75 & 72.29 & Good \\
\hline 2. Strategic Planning & 85 & & & & \\
\hline a. Strategy Development & 40 & 31.40 & & & \\
\hline b. Strategy Implementation & 45 & 35.10 & 66.50 & 78.24 & Very Good \\
\hline 3. Customer Focus & 85 & & & & \\
\hline a. Voice of Customer & 45 & 32.85 & & & \\
\hline b. Customer Engagement & 40 & 30.60 & 63.45 & 74.65 & Good \\
\hline 4. Measurement, Analysis and Knowledge & 90 & & & & \\
\hline $\begin{array}{l}\text { a. Measurement, Analysis, and Improvement of Organizational } \\
\text { Performance }\end{array}$ & 45 & 34.65 & & & \\
\hline $\begin{array}{l}\text { b.Knowledge Management, Information, and Information } \\
\text { Technology }\end{array}$ & 45 & 32.18 & 66.83 & 74.25 & Good \\
\hline 5. Workforce Focus & 85 & & & & \\
\hline a. Workforce Enviroment & 40 & 30.80 & & & \\
\hline b. Workforce Engagement & 45 & 35.10 & 65.90 & $\mathbf{7 7 . 5 3}$ & Very Good \\
\hline 6. Operation Focus & 85 & & & & \\
\hline a. Work Proccesses & 45 & 34.88 & & & \\
\hline b. Operational Effectiveness & 40 & 29.40 & 64.28 & 75.62 & Very Good \\
\hline 7. Result & 450 & & & & \\
\hline a. Health Care and Process Outcome & 120 & 92.40 & & & \\
\hline b. Customer-Focused Outcome & 90 & 70.65 & & & \\
\hline c. Workforce-Focused Outcomes & 80 & 61.20 & & & \\
\hline d. Leadership and Governance Outcomes & 80 & 61.60 & & & \\
\hline e. Financial and Market Outcomes & 80 & 62.80 & 348.65 & 77.48 & Very Good \\
\hline Total & 1000 & 762.35 & 762.35 & & Very Good \\
\hline
\end{tabular}

\section{a. Profil Organisasi}

Kinerja organisasi berdasarkan profil organisasi Rumah Sakit Xdengan nilai 74.50, dimana hal ini merupakan nilai yang baik untuk situasi rumah sakit saat ini berdasarkan penilaian dari responden. Variabel yang dikaji meliputi: visi, misi, nilai dan budayarumah sakit, yang semuanya tersebut menggambarkan ketersediaan pelayanan rawat inap, kelengkapan pedoman pelaksanaan pelayanan rawat inap, dan kelayakan dan kesesuaian fasilitas, peralatan, dan teknologi di unit rawat inap. Berrdasarkan Undang-Undang Republik Indonesia Nomor 44 tentang Rumah Sakitmenyebutkan bahwa peralatan dan prasarana rumah sakit harus memenuhi standar pelayanan dan persyaratan mutu, keamanan, keselamatan dan kesehatan kerja, dan harus dalam keadaan terpelihara dan berfungsi dengan baik.

\section{b. Kriteria Kepemimpinan}

Nilai kepemimpinan senior diperoleh sebesar 50.75 dan nilai pelayanan dan tanggungjawab social diperoleh sebesar 36.00. Nilai total dari kriteria kepemimpinan sebesar 86.75 dari total 120atau sebesar $72.29 \%$, sehingga termasuk dalam kategori baik. Hal ini sesuai dengan yang dinyatakan oleh Sihotang (2007) bahwa kepemimpinan merupakan faktor yang sangat penting dan menentukan keberhasilan suatu organisasi. Adanya gaya kepemimpinan yang berbeda pada pegawai akan menentukan hasil kinerja yang berbeda.

\section{c. Perencanaan Stratejik}

Nilai kriteria perencanaan strategic seebsar 66.50, dimana strategi pengembangan bernilai 31.40 dan strategi implementasi bernilai 35.10. Total dari kriteria ini adalah sebesar $78.24 \%$ berarti mempunyai nilai kinerja yang sangat baik. Sebagaimana dijelaskan bahwa perencanaan mempunyai peran 
mengarahkan organisasi dan menetapkan prosedur terbaik dalam mencapai tujuan yang telah disusun (Haksama, 2016). Perencanaan merupakan pedoman pengawasan dan pengukuran kemajuan dan mempengaruhi kinerja organsasi (Fening, et.al, 2008).

\section{d. Kriteria Fokus Pelanggan}

Nilai kriteria fokus pelanggan adalah sebesar 63.45 atau $74.65 \%$ dari nilai total 85 , artinya mempunyai nilai baik. Pengukuran nilai suara pelanggan diperoleh hasil 32.85 dan keterikatan pelanggan adalah 30.60. Setiawan (2011) menyebutkan bahwa fokus pelanggan merupakan hal yang sangat penting bagi rumah sakit dimana dengan memprioritaskan pasiendapat meningkatkan nilai jasa pelayanan kesehatan yang diberikan.

\section{e. Kriteria Pengukuran, Analisis, dan Manajemen Pengetahuan}

Kriteria ini merupakan kriteria pengukuran, analisis, dan pengelolaan manajemen. Kriteria ini merupakan kriteria penting dimana suatu pengetahuan perlu untuk senantiasa dikelola dengan baik agar dapat disebarkan ke seluruh pegawai di rumah sakit. Nilai yang diperoleh dari pengukuran pada measurement, analysis, and improvement of organizational performance adalah sebesar 34.65, sedangkan kriteria knowledge management, information, and information technology mempunyai nilai 32.18 yang apabila dijumlahkan seluruhnya adalah sebesar 66.83 atau $74.25 \%$ dari nilai total 90 kriteria ini. Nilai kriteria pengukuran, analisis, dan manajemen pengetahuan termasuk pada kategori kinerja baik. Penelitian yang dilakukan oleh Abqari dan Haksama (2013) di RSUD dr. H. Moh. Anwar Sumenep menunjukkan bahwa terdapat kontribusi penting dari kriteria ini dengan peningkatan kinerja rumah sakit. Sedangkan Fening, Pesakovic, dan Amaria (2008) menyebutkan bahwa implementasi yang tepat dari analisis dan informasi akan meningkatkan kinerja suatu organisasi.

\section{f. Kriteria Fokus Sumber Daya Manusia}

Gaspersz (2011) menyatakan bahwa kesuksesan suatu organisasi sangat bergantung pada pengetahuan, keterampilan, kreativitas, motivasi, dan latar belakang pegawainya. Dari penelitian yang dilakukan Fening, Pesakovic, dan Amaria (2008) menyebutkan bahwa fokus sumberdaya manusia merupakan kriteria kuat yang dapat mempengaruhi kinerja organisasi. Nilai yang diperoleh dari hasil penelitian adalah lingkungan kerja sebesar 30.80 dan keterikatan pekerjaan dengan nilai sebesar 35.10 dimana totalnya adalah 65.90 dengan persentase sebesar $77.53 \%$ yang masuk ke dalam kriteria sangat baik.

\section{g. Kriteria Fokus Kegiatan Operasional}

Nilai kriteria focus kegiatan operasional adalah sebesar 64.28 atau sebesar $75.62 \%$ dari total nilai 85 . Berarti masuk ke dalam kriteria sangat baik. Nilai tersebut disumbangkan dari nilai proses kerja sebesar 34.88 dan efektivitas operasional dengan nilai sebesar 29.40. Simanjuntak (2011) menyampaikan bahwa keberhasilan suatu organisasi ditentukan oleh kemampuan organisasi tersebut dalam menyesuaikan diri dengan perubahan yang terjadi. Oleh karena itu, focus pada kegiatan operasional yang meliputi aspek sistem kerja dan proses kerja menjadi sangat penting. Abqari dan Haksama (2016) menyebutkan bahwa terdapat hubungan antara proses manajemen dengan kinerja pelayanan, karena itu proses kerja perlu ditingkatkan dengan baik dan seksama agar kinerja dapat meningkat.

\section{h. Kriteria Hasil}

Kriteria hasil terdapat 5 item yang mana hasil pelayanan kesehatan dan proses mempunyai nilai 92.40; hasil fokus pelanggan sebesar 70.65; focus sumberdaya manusia diperoleh nilai sebesar 61.20; hasil kepemimpinan dan pelayanan dengan nilai 61.60; dan hasil finansial dan pasar sebesar 62.80. Jumlah keseluruhan kriteria hasil adalah 348.65 berarti sebesar $77.48 \%$ dari nilai total kriteria hasil sebesar 450 , hal ini menunjukkan 
bahwa kriteria hasil mempunyai nilai yang sangat baik.

Pada dasarnya kriteria kinerja Malcolm Baldrige ini lebih mengutamakan pada aspek hasil daripada kriteria lainnya, sehingga persentase nilai terbesar dari Malcolm Baldrige ini adalah kriteria hasil. Sebagaimana tercantum pada rerangka kerja Malcolm Baldrige yang didasarkan dari National Institute of Standards and Technology (2011) menyebutkan bahwa kriteria hasil merupakan kriteria utama yang memiliki nilai poin paling tinggi 450. Penelitian Fening, Pesakovic, dan Amaria (2008) menunjukkan bahwa terdapat bukti hubungan yang positif antara hasil proses operasional dan produk dengan kinerja organisasi.

Secara keseluruhan pengukuran dan penilaian yang ditunjukkan pada tabel 1 di atas adalah nilai tertinggi adalah pada kriteria hasil sebesar 348.65. Kriteria yang mempunyai nilai tinggi berikutnya adalah kepemimpinan dengan nilai 120. Malcolm Baldrige mementingkan leadership karena telah terdapat bukti bahwa peran pemimpin mempunyai fungsi yang strategis dalam keberhasilan kinerja suatu organsiasi.Hasil penelitian Sholihah dan Haksama (2014) menunjukkan bahwa kepemimpinan merupakan kunci utama dari keberhasilan kinerja suatu rumah sakit. Keberanian pimpinan dalam mengambil keputusan dan menyelesaikan masalah dapat meningkatkan kepercayaan pegawai, sehingga kinerja dapat meningkat.

Nilai keseluruhan standar dari kriteria kinerja Malcolm Baldrige adalah 1000, sedangkan dari hasil pengukuran pada penelitian ini diperoleh nilai keseluruhan adalah sebesar 762.35. Nilai tersebut masuk ke dalam kriteria sangat baik, dimana hal ini menunjukkan bahwa kinerja Rumah Sakit X telah melaksanakan kinerja secara excellent setelah dilakukan penelitian pengukuran kinerja berdasarkan pada kriteria kinerja Malcolm Baldrige.

Nilai yang terdapat pada kriteria kinerja Malcolm Baldrige merupakan nilai yang dibuat dalam rangka menunjukkan tingkat kepentingan dari masing-masing kriteria terhadap kinerja suatu organisasi. Nilai tersebut berbeda antara satu kriteria dengan kriteria lainnya. Seiring dengan berjalannya waktu, kriteria kinerja Malcolm Baldrige mengalami beberapa perubahan nilai poin maksimal pada sub kriteria untuk menyesuaikan dengan keadaan dan kebutuhan global saat ini. Kriteria hasil memberikan kontribusi nilai paling tinggi pada penilaian kinerja Rumah Sakit X karena Malcolm Baldrige merasakan begitu pentingnya kriteria hasil sebagai kriteria final yang mencakup semua hasil penting pada suatu organisasi.

Dalam mengukur kinerja rumah sakit dapat menggunakan kriteria kinerja Malcol Baldrige karena metoda ini dapat diimplementasikan pada semua organisasi. Dengan adanya pengukuran kinerja tersebut, maka dapat diketahui gambaran dan kondisi rumah sakit yang seperti bagaimana. Dengan diperolehnya gambaran tersebut, pihak manajemen rumah sakit dapat mengembangkan kebijakan, pengambilan keputusan, dan berbagai upaya penyelesaian masalah untuk berupaya meningkatkan kinerja rumah sakitnya agar dapat bersaing dengan rumah sakit lain dan tetap survive dalam memberikan pelayanan kesehatan kepada masyarakat. 


\section{KESIMPULAN}

1. Berdasarkan kriteria kinerja Malcolm Baldrige diperoleh hasil bahwa kinerja Rumah Sakit X termasuk dalam kategori sangat baik pada kriteria perencanan strategis, focus sumberdaya manusia, focus operasional, dan kriteria hasil.

2. Pada kriteria kepemimpinan, focus pelanggan, dan pengukuran analisis dan manajemen pengetahuan berada pada kategori baik.

3. Nilai kinerja Rumah Sakit $X$ secara keseluruhan adalah 762.35 yang berada pada kategori sangat baik.

\section{Rekomendasi}

1. Rumah Sakit $X$ tetap perlu focus meningkatkan kinerjanya dengan meningkatkan kriteria yang masih dalam kondisi baik.

2. Rumah Sakit perlu mempertahankan kriteria yang sudah baik dengan senantiasa melakukan monitoring dan pengawasan pada kriteria dengan nilai sanga baik.

3. Rumah Sakit $X$ perlu melakukan pengukuran dan penilaian kinerja rumah sakit secara berkelanjutan minimal satu tahun sekali agar diperoleh trend atau kecenderungan yang terjadi apakah pelayanannya menurun dan meningkat.

\section{DAFTAR PUSTAKA}

Abqari, U; Haksama, S. (2013). Organization Performance Analysis Based on Malcolm Baldrige in Inpatient Unit of dr.H. Moh. Anwar General Hospital Sumenep. Jurnal Administrasi Kesehatan Indonesia Volume 1 Nomor 4 SeptemberDesember 2013. Fakultas Kesehatan Masyarakat, Universitas Airlangga, Surabaya. E-Mail: El_Carim@Yahoo.Com

Al-Swidi, A.K. dan R. Mahmod. (2011). Fostering the Performance of Banks through Total Quality Management (TQM) Practices: A Bank Branches Perspective. European Journal of Social Sciences, Volume 19, Number 22011

Brown, M.G. (2008). Baldrige Award Winning Quality, Seventeenth Edition Covers the 2008 Award, How to Interpret the Baldrige Criteria for Performance Excellence. New York: CRC Productivity Press

Eker, M. dan S. Eker. (2009). An Empirical Analysis of the Association between the Organizational Culture and Performance Measurement Systems in the Turkish Manufacturing Sector. Journal of Economic and Social Research,11(2) 2009, 43-76

Fening, F.A., G. Pesakovic, dan P. Amaria. (2008). Relationship between quality management practices and the performance of small and medium size enterprises (SMEs) in Ghana. International Journal of Quality \& Reliability Management, Vol. 25 No. 7, 2008 pp. $694-708$

Gaspersz, V. (2011). Sistem Manajemen Kinerja Terintegrasi Balanced Scorecard dengan Malcolm Baldrige dan Lean Six Sigma Supply Chain Management Contoh Implementasi pada Organisasi Bisnis dan Pemerintah. Bogor: Vinchristo Publication.

Haksama, S; Lusno, MFD. (2015). Effort to Improve The Quality Of Health Care Based On Spiderweb Matrix In Puskesmas X Region Y. Proceeding of The 2ndInternationalConference on Entrepreneurship 2015, which published in September 2015.

Haksama, S. (2016). Improving Health Care Based on CustomerSatisfaction Index in FakfakDistrict HospitalWest Papua Province. Proceeding of the Third InternationalConference on Entrepreneurship 2016. Book Two. 
Kementerian Kesehatan RI. (2009). Undang Undang Republik Indonesia Nomor 44 Tahun 2009 tentang Rumah Sakit. Jakarta:Tidak dipublikasikan

Kotler, P. dan G. Armstrong. (2011). Principles of Marketing 14th Edition. New Jersey: Pearson Prentice Hall

Markos, S. dan M.S. Sridevi. (2010). Employee Engagement: The Key to Improving Performance. International Journal of Business and Management, Vol.5 No.12 December 2010

National Institute of Standards and Technology. (2011). 2011-2012 Health Care Criteria for Performance Excellence. Gaithersburg: National Institute of Standards and Technology. http://www.nist.gov/baldrige/publication s/upload/2011_2012_Health_Care_Crite ria.pdf

Nurhapna; Haksama, S. (2014). Effect of Strategic Planning on the Hospital Performance. Jurnal Administrasi Kesehatan Indonesia Volume 2 Nomor 2 April-Juni 2014. Fakultas Kesehatan Masyarakat, Universitas Airlangga, Surabaya. E-mail: nurhapna_oktavia@yahoo.com

Sabarguna, B.S. (2011). Buku Pegangan Mahasiswa Manajemen Rumah Sakit Jilid 1. Jakarta: CV Sagung Seto

Seong, J.Y. (2011). The Effects of High Performance Work Systems, Entrepreneurship and Organizational Culture on Organizational Performance. Seoul Journal of Business, Volume 17, Number 1 (June 2011)

Serfontein, K. dan J. Hough. (2011). Nature of the relationship between strategic leadership, operational strategy and organisational performance. South African Journal of Economic and Management Sciences (Online) vol.14 no.4 Pretoria 2011.

Setiawan, S. (2011). Loyalitas Pelanggan Jasa, Studi Kasus Bagaimana Rumah Sakit
Mengelola Loyalitas Pelanggannya. Jakarta: IPB Press

Sholihah, EM; Haksama, S. (2014). Influence of Leadership on the dr. Soegiri GeneralHospital Lamongan Performance. Jurnal Administrasi dan Kebijakan Indonesia (JAKI), Volume 2 Nomor 4. Oktober-Desember 2014. ISSN 23033592. Published: 2014-04 TOC: 7. Halaman 272-280. Fakultas Kesehatan Masyarakat, Universitas Airlangga, Surabaya. E-mail: dhiendra_27@yahoo.com

Simanjuntak, P.J. (2011). Manajemen \& Evaluasi Kinerja Edisi 3. Jakarta: Lembaga Penerbit Fakultas Ekonomi Universitas Indonesia. 